\title{
Institutionalizing early vaccination of newborns delivered at government health facilities: Experiences from India
}

\author{
Taneja $\mathbf{G}^{1}$, Mentey $\mathrm{VK}^{2}$, Jain $\mathbf{M}^{3}$, Sagar $\mathrm{KS}^{4}$, Tripathi $\mathbf{B}^{5}$, Favin $\mathbf{M}^{6}$, Steinglass $\mathbf{R}^{7}$ \\ ${ }^{1}$ Dr. Gunjan Taneja, Maternal and Child Integrated Program (MCHIP)/India, now with IPE Global / State RMNCH+A \\ Unit, Jharkhand, India, ${ }^{2}$ Dr.Vijaya Kiran Mentey, MCHIP/India, now with MR Medical College for Women, Hyderabad, \\ ${ }^{3}$ Dr. Manish Jain, MCHIP/India, now with India, Health Action Trust/Technical Support Unit, Uttar Pradesh, India, ${ }^{4}$ Dr. \\ Karan Singh Sagar, MCHIP/India. now with GAVI, Geneva, Switzerland, ${ }^{5}$ Dr. Bhupendra Tripathi, MCHIP / India, now \\ with Bill and Melinda Gates Foundation, Delhi, India, ${ }^{6} \mathrm{Mr}$. Micheal Favin, MCHIP, now with the Maternal and Child \\ Survival (MCSP) Project and The Manoff Group, Washington DC, USA, ${ }^{7}$ Mr. Robert Steinglass, MCHIP, now with \\ MCSP and John Snow,Inc, Washington DC, USA.
}

Address for Correspondence: Dr. Gunjan Taneja, Email: gunjan_mgm@yahoo.co.in

\begin{abstract}
Newborn Vaccination is identified as a critical parameter for evaluating the overall performance of immunization programs with guidelines clearly advocating for administration of BCG, OPV zero dose and Hepatitis B birth dose to newborns. However in spite of sustained improvement in full immunization coverage in India, coverage of newborn vaccines has remained traditionally low.The USAID supported Maternal and Child Health Integrated Program (MCHIP), operational in India from 2009 - 2014 provided technical support to the Universal Immunization Program (UIP) at the National level and in the states of Jharkhand and Uttar Pradesh. During the project period, MCHIP undertook an assessment in 46 selected health facilities across 5 districts of the two states to study the implementation of the newborn vaccination program. Key findings from the assessment included a lack of knowledge among staff about the benefits of newborn vaccination, absence of written guidelines, unavailability of one vaccine compromising the administration of the remaining two and poor documentation practices.
\end{abstract}

Following the assessment technical support was provided to strengthen implementation at these selected facilities which included providing on-the-job orientations to staff members posted in delivery rooms, establishing a sound supply chain mechanism to ensure round the clock availability of vaccines in labour rooms, strengthening documentation by incorporating separate columns in the delivery registers for recording vaccine administration and improved Supportive Supervision mechanisms. The intervention produced favorable results with a progressive increase in coverage of not only BCG and OPV zero dose but also Hepatitis B birth dose which was introduced in the UIP during the course of the intervention.

Overall this intervention, which focused on operationalizing an already existing strategy, clearly indicated that the practice of vaccinating newborns delivered at health facilities is easily implementable and replicable, and that its sustainability should ensure improved coverage and protection against targeted vaccine-preventable diseases.

Keywords: Immunization, newborn vaccination, Early vaccination

\section{Background}

The efficacy of different vaccines in preventing certain serious childhood illnesses has been well proven. Although children inherit a degree of passive immunity from their mothers' blood, it remains essential that all

Manuscript received: $11^{\text {th }}$ May 2015

Reviewed: $14^{\text {th }}$ May 2015

Author Corrected: $24^{\text {th }}$ May 2015

Accepted for Publication: $1^{\text {st }}$ June 2015 infants are vaccinated against specific infectious diseases at the appropriate age to develop protective immunity against the Vaccine Preventable Diseases (VPDs) including vaccinating newborns with birth doses. This practice, which contradicts a common but groundless fear of overwhelming newborns' immune system, is in fact helpful in boosting immunity, 
preventing early infections and priming an antigenic response to subsequent doses of particular vaccines. The World Health Organization (WHO) recommends administration of three vaccines, viz. Oral Polio Vaccine (OPV), BCG and Hepatitis B vaccine, as early as possible after birth. These recommendations are specified in Vaccine Position Papers that provide guidance to policy makers, public health officials and program managers of member countries. The evidencebased benefits of early administration of these vaccines are well documented, as described below:

- As we inch towards polio eradication, ensuring the earliest possible immunity shield to newborns assumes great significance. This necessitates administration of a birth dose of OPV (known as zero dose because it does not count towards the primary series) in all polio endemic countries and in countries at high risk for importation and subsequent spread [1]. According to research OPV administered at birth or as soon as possible after birth can significantly improve the sero-conversion rates of subsequent doses and induce mucosal protection before enteric pathogens can interfere with the immune response [2].

- One dose of BCG vaccine as soon as possible after birth is recommended in countries with a high burden of tuberculosis (like India) in order to provide protection against $\mathrm{TB}$ meningitis and disseminated TB disease (although this dose is not very helpful in preventing infection and transmission of the pathogen) [3].

- One dose of Hepatitis B vaccine within 24 hours of birth (birth dose) helps prevent perinatal transmission of infection, which accounts for more than one third of chronic infections in areas of low endemicity. A delay in the birth dose results in an increased risk of Hepatitis B infection [4]. WHO also advocates using this birth dose as a critical indicator for measuring performance of immunization programs.

India's Universal Immunization Program recommends a nationwide immunization schedule specifying the vaccines, doses and appropriate ages for vaccination [5]. This schedule is revised periodically in light of new evidence and the introduction of new vaccines and vaccine products. The national immunization schedule aligns with WHO recommendations and gives due emphasis to birth vaccines for newborns, viz. one dose of trivalent OPV (referred as zero dose) within 15 days of birth, Hepatitis B (referred as the birth dose) within 24 hours of birth and BCG vaccine as early as possible after birth.

As a result of conspicuous interest shown by national and state governments, development partners and other stake-holders, India's immunization program is one of the country's leading national public health programs. Different evaluations conducted throughout the years have substantiated gradual improvements in immunization coverage since the inception in 1978 of the Expanded Program on Immunization (EPI). The National Family Health Survey (NFHS) series have revealed increases in the proportion of fully immunized children in the country from $35.4 \%$ (1992-93 [6] to $43.5 \%$ (2005-06) [7] with concomitant increases in coverage of other antigens. The District Level Household Survey (2007-08) [8] and more recent Coverage Evaluation Survey (CES 2009) [9] showed full immunization coverage as $53.5 \%$ and $61 \%$ respectively.

On the other hand, the coverage status of birth vaccines, except for BCG, is relatively low, and shows wide variations across the states. BCG coverage is comparatively better because the age limit for this vaccine is up to one year, and may be higher than reported because there is no concrete mechanism yet to capture BCG administered to institutionally delivered new-borns before they are discharged from the facility. Though the Maternal and Child Tracking System (MCTS) an online portal to ensure timely follow-up and delivery of an entire package of promotive and preventive services to all beneficiaries does provide an option to link birth date and the day of vaccination; delayed entries and updatation often leads to poor utilization of the system. If these vaccinations could somehow be reported through the Health Management Information System (HMIS) and MCTS in a timely manner, then it is quite possible that early BCG coverage might be similar to other birth vaccines, although possibly lower due to associated fear of wastage, as discussed in the subsequent sections. The coverage status of newborn vaccines vis a vis fully immunized status as per different evaluation surveys is given in Table 1. 
Table 1: National Coverage of all and newborn vaccines as per different evaluations

\begin{tabular}{|c|c|c|c|c|}
\hline Evaluation survey & $\begin{array}{l}\text { Fully } \\
\text { immunized }\end{array}$ & BCG coverage & $\begin{array}{l}\text { OPV zero dose } \\
\text { coverage }\end{array}$ & $\begin{array}{l}\text { Hep B birth dose } \\
\text { coverage * }\end{array}$ \\
\hline NFHS 1 (1992-93) & $35.4 \%$ & $\begin{array}{l}62.2 \% \\
\text { (Range: } 93.5 \% \text { Goa - } \\
19.4 \% \text { Nagaland) }\end{array}$ & $\begin{array}{l}4.6 \% \\
\text { (Range: } 19.4 \% \text { Tamil } \\
\text { Nadu }-0.8 \% \text { Tripura) }\end{array}$ & \\
\hline NFHS 3 (2005-06) & $43.5 \%$ & $\begin{array}{l}78.1 \% \\
\text { (Range: } 99.5 \% \text { Tamil } \\
\text { Nadu }-46.3 \% \\
\text { Nagaland) }\end{array}$ & $\begin{array}{l}48.4 \% \\
\text { (Range: } 94.5 \% \text { Tamil } \\
\text { Nadu - } 13.2 \% \\
\text { Nagaland) }\end{array}$ & \\
\hline DLHS 3 (2007-08) & $53.5 \%$ & $\begin{array}{l}86.7 \% \\
\text { (Range: } 100 \% \\
\text { Lakshadweep - } \\
73.3 \% \text { Uttar Pradesh) }\end{array}$ & $\begin{array}{l}20.1 \% \\
\text { (Range: } 100 \% \\
\text { Puducherry }-33.1 \% \\
\text { Rajasthan) }\end{array}$ & \\
\hline CES (2009) & $61 \%$ & $\begin{array}{l}86.9 \% \\
\text { (Range: } 100 \% \\
\text { Sikkim }-66.1 \% \\
\text { Nagaland) }\end{array}$ & $\begin{array}{l}66 \% \\
\text { (Range: } 92.3 \% \\
\text { Maharashtra - } 19.5 \% \\
\text { Nagaland) }\end{array}$ & $29.2 \%$ \\
\hline
\end{tabular}

* Hepatitis B vaccination was included in National Immunization Schedule from 2007-08 in phased manner across different states of the country

The Government of India launched the Janani Suraksha Yojna (JSY) (the Maternal Protection Scheme) in 2005 under the National Rural Health Mission (NRHM), now the National Health Mission (NHM), with the immediate objective of promoting universal access to institutional deliveries by providing a financial package to pregnant woman. JSY is considered a key strategy for achieving the goal of bringing down the maternal mortality ratio to $100 / 100,000$ by the end of the Twelfth Five Year Plan (2012-17). This scheme resulted in a significant increase in the proportion of institutional deliveries from $47 \%$ [8] to $72.9 \%$ [9].

With progressive improvements in immunization coverage rates and the rising trend of institutional deliveries across the country vaccination of newborns assumes greater importance. This practice not only ensures timely protection of newborns against three infections but also facilitates early registration in health records, follow-up for routine immunization and appropriate care during infancy and childhood. But despite the importance of this intervention, it is not practiced universally across different states/districts as shown by wide differences in coverage of BCG and OPV zero-dose across different states of the country.

In order to understand the underlying constraints and conceptualize a practical roadmap to ensure timely vaccination of newborns across all health facilities where deliveries are conducted, the USAID supported Maternal and Child Health Integrated Program (MCHIP) which was operational in the country from 2009-2014 and provided technical support to the Universal Immunization Program (UIP) at the National level and in the two focus states of Jharkhand and Uttar Pradesh undertook an assessment, followed by intervention in five focus districts in the two states.

\section{Program Description}

\section{Assessment}

During the course of the project, the MCHIP team provided technical support for strengthening immunization programs in two focus districts of Jharkhand (Deoghar and Jamtara) and three districts of Uttar Pradesh (Banda, Gonda and Varanasi) between October 2009 and August 2013.

In order to understand the implementation status of newborn vaccination and the knowledge and practices followed by the health staff an assessment was done initially in 46 district and sub-district level health facilities in these 5 focus districts. The criteria for selection of health facilities were: (1) a functional cold chain point where vaccines are stored and (2) a functional delivery room where deliveries are being conducted. The assessment involved discussion with concerned staff members regarding their practices for 
newborn vaccination and awareness regarding any government order to pursue the same. Besides this, the available records (e.g. the delivery register and immunization clinic register) and reports (monthly facility reports) were reviewed and data collected on number of newborns delivered and vaccinated in these facilities. The assessment was done between January 2011 and June 2011, and retrospective newborn vaccination data were also collected for the same period.

It was observed that at almost all the facilities, deliveries were conducted by Staff Nurses or Auxiliary Nurse Midwives (ANMs). The staff members knew that BCG and OPV vaccines needed to be administered to newborns before the mother is discharged from the facility but were not aware of any written instructions to vaccinate newborns following birth. They also were not aware of the additional benefits provided by early administration of these vaccines after delivery.

India was not following the 'Open Vial Policy' for liquid vaccines before October 2011. This constituted an important reason for not vaccinating each and every newborn, due to health workers' concerns about increased wastage of vaccines from opening a multidose vial for fewer children than doses in the vial. This is particularly pertinent for BCG vaccine, which is freeze-dried. As per relevant operational guidelines, all remaining reconstituted vaccine doses must be discarded four hours after mixing the diluent [5]. Even the facility in charges and district -level program managers were reluctant to open a new vial for a single newborn (although guidelines do recommend this) owing to increased wastage and possible query from the supervisors into the matter.

Generally, the birth vaccines (BCG and OPV) were administered at the same time so the unavailability of one vaccine compromised the administration of another. It was also observed that vaccination was conducted only during the clinic hours and not round the clock. As a result of this, infants delivered during the non-clinic hours were often not vaccinated. In some facilities no institutional mechanism existed for administering birth doses. In addition it was observed that there was no structured mechanism for keeping vaccines in the delivery room in proper cold chain conditions. The practices followed indicated informal arrangements between the delivery room staff and the cold chain handler.
Another important aspect revealed was related to the recording system, which was found to be variable at different health facilities. Non-uniform methods of recording and recording templates indicated a lack of coordination between program managers looking after maternal health, child health and immunization programs. It was observed that in a majority of facilities, the delivery registers had no provision of recording vaccinations provided, which contributed to non-compliance with the guidelines and moreover lack of standardized formats compromised the recording and reporting of newborn vaccinations in both the states.

Data on newborn vaccination was collected both in discussions with staff members and from the delivery registers (and other available records e.g. immunization clinic register) at all 46 health facilities, compiled and analysed for period from January 2011 to June 2011 against total deliveries taking place to serve as denominator. It was revealed that approximately one third of new-borns being delivered at these government health facilities were receiving BCG vaccine and OPV zero dose $(36.6 \%$ and $33.4 \%$ newborn receiving $\mathrm{BCG}$; $36.8 \%$ and $38.8 \%$ receiving OPV zero dose in Jharkhand and Uttar Pradesh respectively). Since Hepatitis B vaccine was included in the immunization schedule only after October 2011, no data was available for it.

Overall this assessment highlighted an important service delivery issue, as well as a missed opportunity to inform mothers about the need for vaccination, thus contributing towards well established reasons for unimmunized and partially-immunized children in India of $26.3 \%$ parents of partially or unimmunized children being unaware of what vaccines are needed and when and another $28.2 \%$ parents lacking a felt need for immunization [9]. Better-organized newborn vaccination might have provided an opportunity to make parents appreciate the importance of immunization and vaccines. This prevailing situation demanded both improvements at all levels including the health facilities to ensure that appropriate policy framework and functional monitoring and review mechanisms are in place.

\section{Intervention}

Rather than immediately sharing the findings with policy makers, it was deemed necessary to devise and test actions to ensure newborn vaccination specifically for newborns delivered at the government health 
facilities - to discover possible challenges and assess how the changes would affect the overall immunization status of the community. Therefore, an intervention to strengthen and institutionalize newborn vaccination was initiated at these 46 health facilities in 5 focus districts of Jharkhand and Uttar Pradesh in July 2011.

As an initial step the district and block level officials and concerned health staff from across these 5 districts were sensitized during review and staff meetings organized at different levels about the assessment findings, existing policy and operational guidelines regarding newborn vaccination and the steps required to address the issue. This was followed by specific actionoriented activities implemented in phased manner over the successive months which included:

- $\quad$ Providing on-the-job orientation to staff nurses and ANMs posted in delivery rooms
- Developing procedures for supplying vaccine carriers with required vaccines and diluents to the delivery room on a 24 hourly basis

- Incorporating separate columns in the delivery registers for recording vaccine administration (or the reason why vaccination could not be done)

- Ensuring regular reporting of newborn vaccinations as part of the on-going daily reporting of deliveries conducted as provisioned under Janani Suraksha Yojna (JSY)

- Routinely assessing this practice during the supervisory visits and review meetings.

The continued advocacy, technical support, feedback and feed-forward within the health department resulted in the gradual adoption of these practices and improvements in coverage among newborns delivered at these health facilities.

The coverage data compiled for 6-month periods (Table 2) revealed progress not only for BCG and zero dose of OPV but also early acceptance and a sharp increase in coverage of the birth dose of Hepatitis B as soon as it was introduced in the immunization schedule in November-December 2011 in both the states.

Table 2: Initial status and progress of newborn vaccination during intervention

\begin{tabular}{|l|l|l|l|l|l|l|l|l|}
\hline \multirow{2}{*}{ Period } & \multicolumn{3}{|l}{$\begin{array}{l}\text { Jharkhand } \\
\text { (2 districts, 13 health facilities) }\end{array}$} & \multicolumn{2}{l}{$\begin{array}{l}\text { Uttar Pradesh } \\
\text { (3 districts, 33 health facilities) }\end{array}$} \\
\cline { 2 - 9 } & $\begin{array}{l}\text { Total } \\
\text { deliveries }\end{array}$ & $\begin{array}{l}\text { BCG } \\
\text { coverage }\end{array}$ & $\begin{array}{l}\text { OPV } \\
\text { zero dose } \\
\text { coverage }\end{array}$ & $\begin{array}{l}\text { Hep B } \\
\text { birth } \\
\text { dose } \\
\text { coverage }\end{array}$ & $\begin{array}{l}\text { Total } \\
\text { deliverie } \\
\text { s }\end{array}$ & $\begin{array}{l}\text { BCG } \\
\text { coverage }\end{array}$ & $\begin{array}{l}\text { OPV } \\
\text { zero dose } \\
\text { coverage }\end{array}$ & $\begin{array}{l}\text { Hep B } \\
\text { birth dose } \\
\text { coverage }\end{array}$ \\
\hline $\begin{array}{l}\text { Jan-Jun' } \\
\mathbf{2 0 1 1}\end{array}$ & 5638 & $36.6 \%$ & $36.8 \%$ & ---- & 30161 & $33.4 \%$ & $38.8 \%$ & ---- \\
\hline $\begin{array}{l}\text { Jul-Dec' } \\
\mathbf{2 0 1 1}\end{array}$ & 9366 & $66.3 \%$ & $61.7 \%$ & $12.0 \%$ & 46825 & $53.1 \%$ & $53.4 \%$ & $1.2 \%$ \\
\hline $\begin{array}{l}\text { Jan-Jun' } \\
\mathbf{2 0 1 2}\end{array}$ & 8692 & $76.2 \%$ & $69.6 \%$ & $69.1 \%$ & 31723 & $55.1 \%$ & $69.0 \%$ & $59.4 \%$ \\
\hline $\begin{array}{l}\text { Jul-Dec' } \\
\mathbf{2 0 1 2}\end{array}$ & 10753 & $79.6 \%$ & $74.4 \%$ & $74.3 \%$ & 43115 & $67.1 \%$ & $78.4 \%$ & $74.7 \%$ \\
\hline $\begin{array}{l}\text { Jan-Jun' } \\
\mathbf{2 0 1 3}\end{array}$ & 9349 & $82.4 \%$ & $83.9 \%$ & $81.3 \%$ & 30249 & $60.6 \%$ & $75.4 \%$ & $64.2 \%$ \\
\hline
\end{tabular}

In terms of numbers, the intervention resulted in timely vaccination of additional 26,000 children with BCG vaccine and 30,000 children with the zero dose of OPV in the 6 months between January and June 2013, numbers which are more than the total number of births occurring annually in countries like Bahrain, Latvia and Qatar [10].

\section{Learnings and Implications}

This intervention, which focused on operationalizing an already existing strategy, clearly resulted in an improved outcome. The results indicate that the practice of vaccinating newborns delivered at health facilities as early as possible after birth is easily implementable and replicable, and that its sustainability should ensure improved immunization coverage and protection against targeted vaccine-preventable diseases. The other benefit was early registration of infants in health facility 
records for subsequent follow-up for complete immunization and other services.

As is true with any other intervention, operationalization of this practice faced hurdles related to different administrative structure and priorities in both the states, leadership issues, inequitable distribution of service providers and facilities, poor Supportive Supervision mechanisms and demand/supply mismatch. The latter issue, due to poor logistics management system, resulted in stock-outs of specific vaccines during the intervention period, which limited increases in coverage.

However, contrary to the prevalent belief, resistance from mothers and caregivers to vaccination of their newborns was minimal; and the prime reason from a beneficiary perspective of newborns not getting vaccinated was mostly related to the fact of mothers not staying over-night or for the required period of time after delivery either due to lack of basic amenities at health facilities or the beneficiaries themselves not staying back due to cultural and social factors. Hence apart from strengthening the supply chain component, demand side issues should be addressed by promoting community awareness for newborn vaccination through outreach activities. This reflects the need to promote at community level the importance of vaccinating newborns delivered both at health facilities and at homes as early as possible.

These easy-to-implement actions resulted in an increased number of newborns vaccinated. This has implications for increasing the coverage rates for the vaccines, early vaccination and immunity, timely tracking and improved quality of service delivery. These facts were appreciated by the state level program managers in Jharkhand and Uttar Pradesh, who issued clear instructions and guidelines to district officials for ensuring vaccination of all newborns delivered at government health facilities with the three vaccines (BCG, OPV and Hepatitis B) before mothers are discharged from the facility. To ensure compliance with this instruction, another government order in these states linked this practice to the ongoing JSY initiative. The latter order instructed district and block-level officials to release JSY incentives only after ensuring that the newborn is vaccinated and an immunization card is issued to the child.

\section{Conclusion}

The importance of early vaccination of newborns with birth vaccines is well established. The results of this intervention in limited geographical areas of Jharkhand and Uttar Pradesh show that advocacy and synchronized technical inputs for capacity building, system strengthening, concurrent monitoring and review can improve practices and help build early immunity against three vaccine-preventable diseases among the newborns delivered at the health facilities. However, implementation and sustainability of desired impact over time requires timely policy reforms in light of scientific advances and evidence appropriately backed with operational guidelines and functional systems.

\section{Acknowledgments}

This article was made possible by the generous support of the American people through the United States Agency for International Development (USAID), under the terms of the Leader with Associates Cooperative Agreement GHS-A-00-08-00002-00. The contents are the responsibility of the Maternal and Child Health Integrated Program (MCHIP) and do not necessarily reflect the views of USAID or the United States Government.

The authors would also like to acknowledge the State Governments of Uttar Pradesh and Jharkhand for allowing the project to undertake the intervention.

\section{References}

1. Weekly Epidemiological Record. WHO position paper on polio vaccines and polio immunization in the pre-eradication era; 2010; 85 (23): 213-228. Available from: http://www.who.int/wer/ 2010/wer8523.pdf; accessed on 11-09-2014

2. Bhaskaram $P$ et al. Systemic and mucosal immune response to polio vaccination with additional dose in newborn period. J Trop Pediatr. 1997 Aug;43(4):232-4.

3. Weekly Epidemiological Record. WHO position paper on BCG vaccine; 2004; 79 (4): 27-38.Available from: http://www.who.int/wer/2004/en/wer7904.pdf; accessed on 11-09-2014

4. Weekly Epidemiological Record. WHO position paper on Hepatitis B vaccine; 2009; 84 (40): 405419.Available from: http://www.who.int/wer/2009/wer8440.pdf; accessed on 11-09-2013 
5. Ministry of Health and Family Welfare. Government of India. Immunization Handbook for Medical Officers; 2009.

6. International Institute for Population Sciences (IIPS) and Macro International. 2000. National FamilyHealth Survey (NFHS-2), 1998-99: India: Volume I.Mumbai: IIPS.

7. International Institute for PopulationSciences (IIPS) and Macro International. 2007. National FamilyHealth Survey (NFHS-3), 2005-06: India: Mumbai: IIPS.
8. International Institute for Population Sciences (IIPS), 2010. District Level Household and Facility Survey (DLHS-3), 2007-08: India: Key Indicators: States and Districts, Mumbai: IIPS.

9. UNICEF Coverage Evaluation Survey, 2009: National Fact Sheet.

10. The State of World's Children: UNICEF, 2013

\section{How to cite this article?}

Taneja G, Mentey VK, Jain M, Sagar KS, Tripathi B, Favin M, Steinglass R. Institutionalizing early vaccination of newborns delivered at government health facilities: Experiences from India. Int J Med Res Rev 2015;3(5):521-527. doi: 10.17511/ijmrr.2015.i5.089. 